\title{
Simulations and measurements on a self-excited induction generator
}

\author{
Jozef Zuščak, Vladimír Kujan, František Janíček*
}

\begin{abstract}
Paper deals with the use of an induction machine in the role of a generator. Such an operational mode is called a selfexcited induction generator SEIG. It does not require an external power source to create the excitation field, as is the case with traditional synchronous generators. Therefore, it is widely used in power plants with renewable energy as a primary source (wind, water, etc). However, in terms of possible regulation and control of the electrical properties, the excitation process is extremely important. A mathematical model and simulation in Matlab are introduced. The excitation process was experimentally investigated in the laboratory of electric drives and the results are correlated with the expectations.

K e y w or d s: SEIG, capacitor, load, saturation, excitation, voltage
\end{abstract}

\section{Introduction}

Increasing demands on electricity supply, coupled with declining machinery and storage battery prices, result in the expansion in the field of isolated (off-grid) power systems. Nowadays, two types of generators are predominantly used for off-grid power supply:

- generator with permanent magnets,

- inductive generator.

The main reason for this is that these machines do not need an external power source to generate the magnetic field of the rotor (excitation), which is needed for conversion of mechanical energy into electricity. This fact is very important. On the other hand, the lack of independent field regulation brings problems with current and voltage control. Especially if the generator is used in combination with a small wind turbine with poor speed control abilities. In this type of operation, undesirable voltage fluctuations can occur. Even the possibility of magnetic field loss resulting in a loss of power can be observed in case the load is increased behind a stable working point. We discuss these as well as other issues, focused on the SEIG, mainly due to its properties like: low unit price, brushless squirrel-cage rotor, low maintenance requirements, and operation without an external source of excitation.

\section{Theoretical and mathematical background}

Operation of the induction generator with a squirrel cage is possible only due to the presence of remanent magnetism in the rotor usually built from magnetically soft materials. Remanent (residual) magnetism is always present thanks to the previous operation of the machine. According to Faraday's law, the moving magnetic field of the rotor will induce voltage in the stator coils. This voltage depends on the excitation current and the speed of rotation. In our case, the excitation current is provided due to a capacitor bank connected to the stator windings.

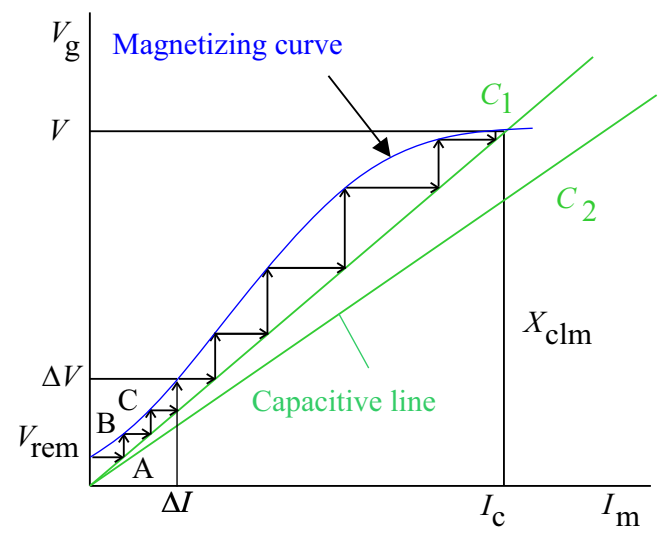

Fig. 1. Self-excitation process

The self-excitation, described in Fig. 1, is a long know process [6]. When the prime mover drives the rotor, the remanent magnetism in the rotor causes the induction voltage across the stator coils with frequency proportional to the speed of rotation. Due to this voltage the capacitor bank connected in parallel provides the stator current flow. The magnetic flux in the machine is raised with rising stator voltage and current. The process continues until the saturation point is reached where the voltage is stable.

The dynamic behaviour of SEIG can be mathematically described by six state equations, providing all currents and voltages can be describeds as

$$
\begin{aligned}
& i(t)=I(t) \cos (\omega t+\phi) \\
& v(t)=V(t) \cos (\omega t+\theta)
\end{aligned}
$$

* Slovak University of Technology in Bratislava, Ilkovičova 3, 81219 Bratislava, Slovakia, jozef.zuscak@stuba.sk, vladimr.kujan@stuba.sk, frantisek.janicek@stuba.sk 


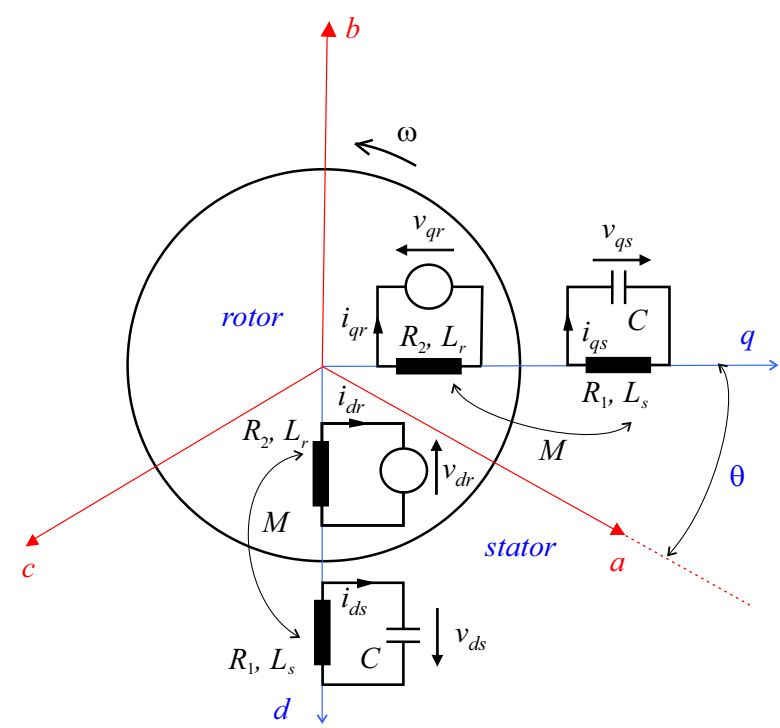

Fig. 2. Park transformation of SEIG with capacitors on stator terminals

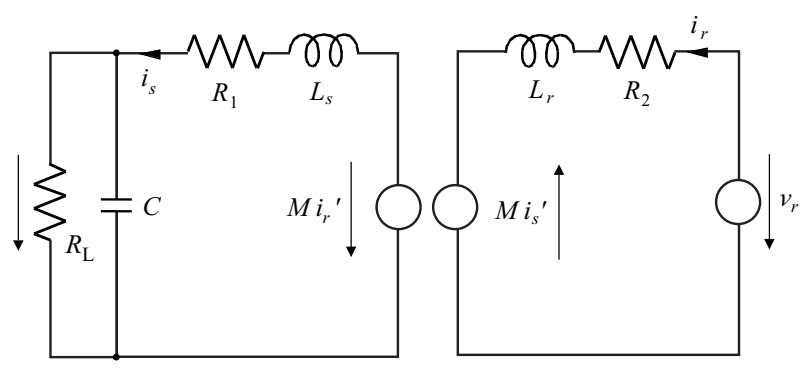

Fig. 3. Equivalent circuit diagram

where amplitudes $I(t), V(t)$ are time dependent until the saturation is reached and $\omega$ - is rotation speed of the prime mover, [1]. Using standard complex representation in equations of the equivalent circuit in Fig. 3: $i(t), v(t) \rightarrow \mathcal{J}(t) e^{j \omega t}, \mathcal{V}(t) e^{j \omega t}$, after the separation into $d$ and $q$-frames, $\mathcal{J}=I_{d}+j I_{q}$ and $\mathcal{V}=V_{d}+j V_{q}$, still with time dependent amplitudes - although we omit the explicit notation for brevity - after some manipulation, the following equations were formulated

\section{Measurments on induction generator}

For simulation and evaluation of the results, several laboratory measurements were performed on a test induction machine:

- Coil resistance test

- No-load test

- Locked rotor test

- Magnetization curve test

First, equivalent circuit, Fig. 3, parameters need to be determined, to be used in simulations. Inductances $L_{r}, L_{s}$ and the mutual inductance $M$, resistances $R_{1}, R_{2}$ of stator and rotor windings, and initial amplitude $V_{r}$ due to remanent induction. The losses in the core were neglected in presented calculations and the load $R_{L}$ (not indicated in Fig. 2) was considered to be purely ohmic (no capacitive nor inductive) in this approach.

\subsection{Parameters of equivalent circuit}

Induction machine plate information: $P=2.2 \mathrm{~kW}$, wound rotor, $n=1400 \mathrm{rpm}, U=380 / 220 \mathrm{~V},(\mathrm{Y} / \mathrm{D})$, $I=5 / 8.6 \mathrm{~A}(\mathrm{Y} / \mathrm{D})$.

The $I-V$ method was used to measure the resistances of the stator $R_{1}=2.935 \Omega$ and rotor $R_{2}=0.145 \Omega$ windings.

The no-load test, similar to the open circuit test on a transformer, was performed to determine the parameters $R_{\mathrm{Fe}}$ and $X_{\mathrm{m}}$ of the equivalent circuit. In this test, Fig. 4, the machine is running free at the rated voltage and the rated frequency without load. The slip is nearly equal to zero and the machine will rotate at almost synchronous speed. This causes the equivalent rotor impedance to be theoretically infinite and the resulting data will give information about the stator and magnetization branch of the equivalent circuit. The actual machine was powered from an induction regulator (booster) to provide a precise sinus rated voltage.

The locked rotor test is very similar to the short circuit test on a transformer. The rotor is locked to prevent rotation and regulated voltage is applied to the stator to achieve the rated machine current, Fig. $4(n=0)$. The slip in this condition is equal to unity since the rotor is standstill.

$$
\begin{aligned}
& \frac{\mathrm{d}}{\mathrm{d} t}\left[\begin{array}{c}
I_{d s} \\
I_{q s} \\
I_{d r} \\
I_{q r} \\
V_{d s} \\
V_{q s}
\end{array}\right]=K\left[\begin{array}{cccccc}
R_{1} L_{r} & -\omega M^{2} & R_{2} M & -\omega M L_{r} & L_{r} & 0 \\
\omega M^{2} & R_{1} L_{r} & \omega M L_{r} & -R_{2} M & 0 & L_{r} \\
R_{1} M & -\omega M & R_{2} L_{s} & -\omega M^{2} & M & 0 \\
-\omega M L_{s} & -R_{1} M & \omega L_{s} L_{r} & R_{2} L_{s} & 0 & -M \\
1 / C K & 0 & 0 & 0 & 0 & 0 \\
0 & 1 / C K & 0 & 0 & 0 & 0
\end{array}\right] \cdot\left[\begin{array}{c}
I_{d s} \\
I_{q s} \\
I_{d r} \\
I_{q r} \\
V_{d s} \\
V_{q s}
\end{array}\right]+ \\
& {\left[\begin{array}{cc}
M & 0 \\
0 & M \\
-L_{s} & 0 \\
0 & -L_{s} \\
0 & 0 \\
0 & 0
\end{array}\right] \cdot\left[\begin{array}{l}
V_{d r} \\
V_{q r}
\end{array}\right], \quad \text { with: } K=\frac{1}{M^{2}-L_{s} L_{2}} }
\end{aligned}
$$




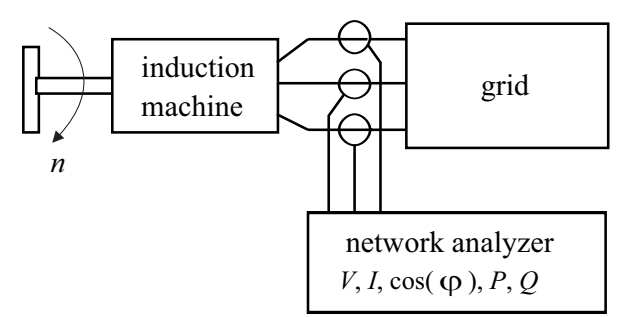

Fig. 4. No-load and locked $(n=0)$ rotor test

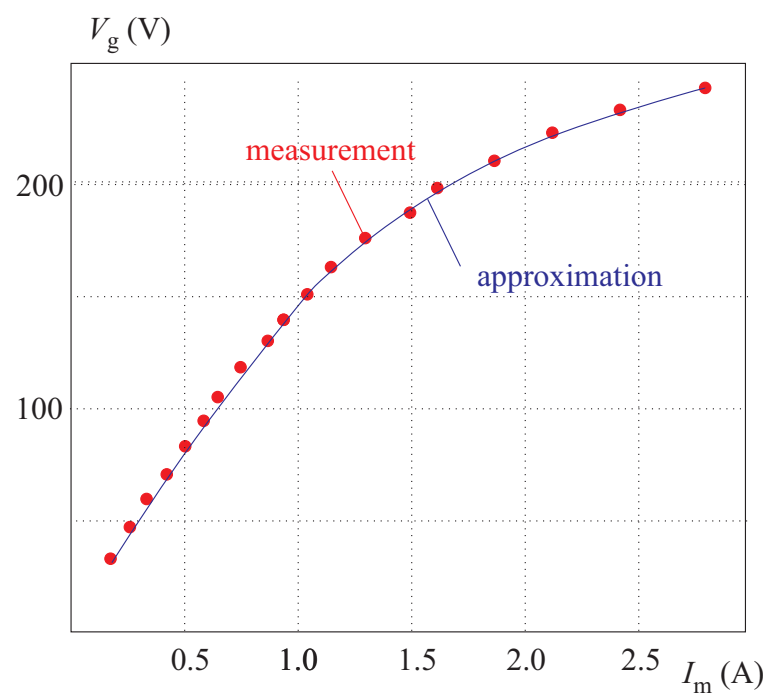

Fig. 6. Measured magnetization curve of the induction machine

If one can say that the impedance of the shunt branch of the equivalent circuit is much higher than that of the longitudinal branch of the circuit, neglecting the excitation branch allows to determine parameters $X_{1}, X_{2}, L_{s}$ and $L_{r}$ from the measurements. Practical test was performed with reduced voltage using an induction regulator (booster).

Results of measurement and the evaluated parameters are summarized in Tab. 1.

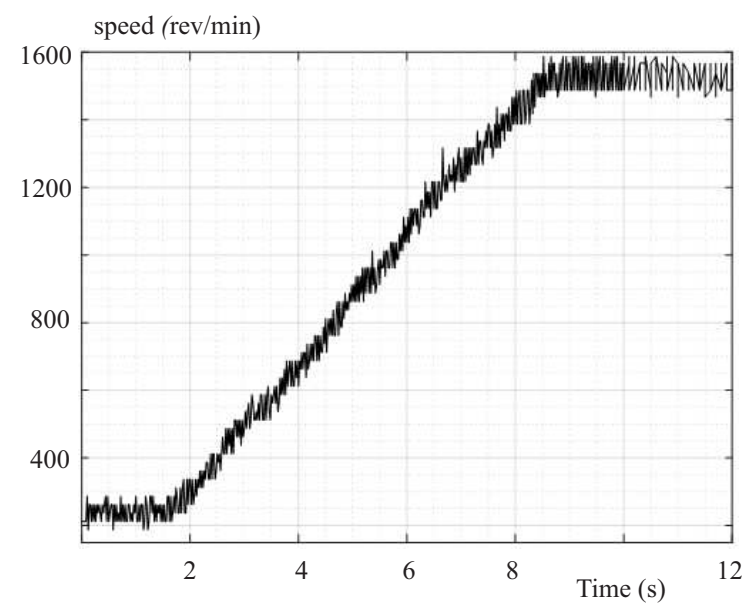

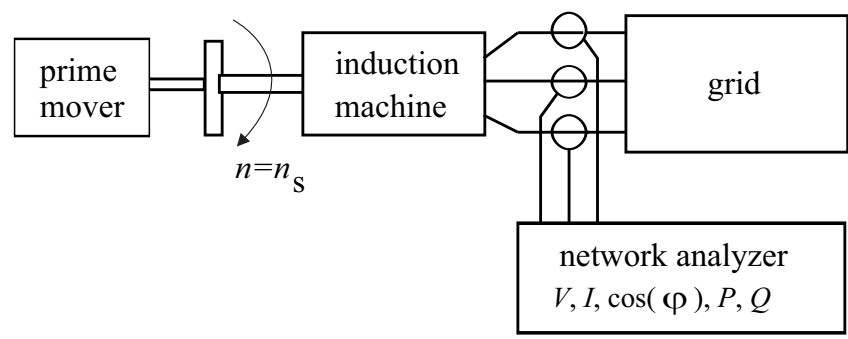

Fig. 5. Magnetizing curve test

Table 1. No-load and locked rotor test

\begin{tabular}{lccc}
\hline & no-load & locked rotor & \\
\hline$U_{L L}$ & 380 & 124 & $\mathrm{~V}$ \\
$I_{L}$ & 2.057 & 5.0 & $\mathrm{~A}$ \\
$P$ & 280 & 616 & $\mathrm{~W}$ \\
$Q$ & 1330 & 904 & $\mathrm{VAr}$ \\
$\cos (\varphi)$ & 0.206 & 0.56 & - \\
\hline
\end{tabular}

After the parameters of equivalent circuit were determined, a measurement giving information about the magnetization curve $-L_{m}=f\left(I_{m}\right)$ dependence was needed. In this case, Fig. 5, the rotor shaft is driven by a DC dynamometer at constant synchronous speed of $1500 \mathrm{rpm}$. The slip becomes equal to the zero and the rotor resistance reaches infinity

$$
s \rightarrow 0 \text { hence } R_{2}^{\prime} \frac{1-s}{s} \rightarrow \infty .
$$

\section{Simulation of SEIG}

Matlab script was written to simulate the self-excited induction machine operation based on (2). Then, parameters of the equivalent circuit calculated from no-load and locked rotor tests were collected.

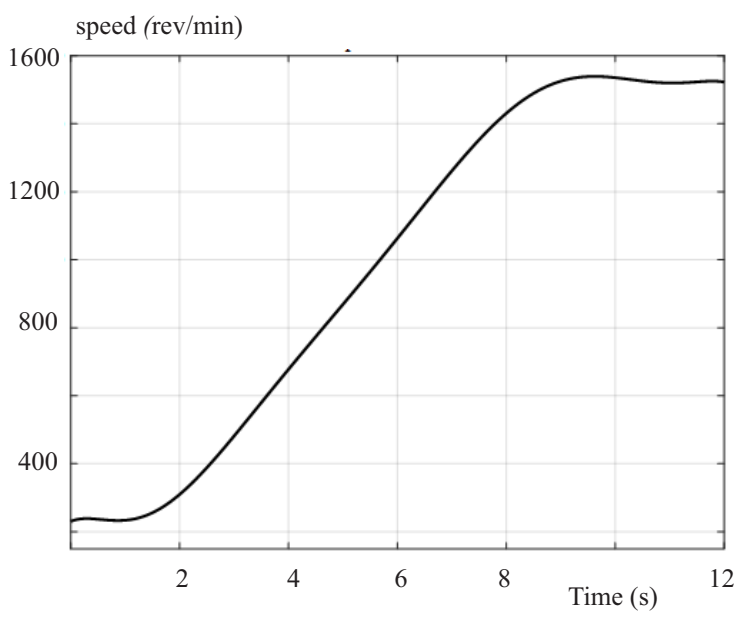

Fig. 7. Speed vs time: (a) - measured, and (b) - simulated 

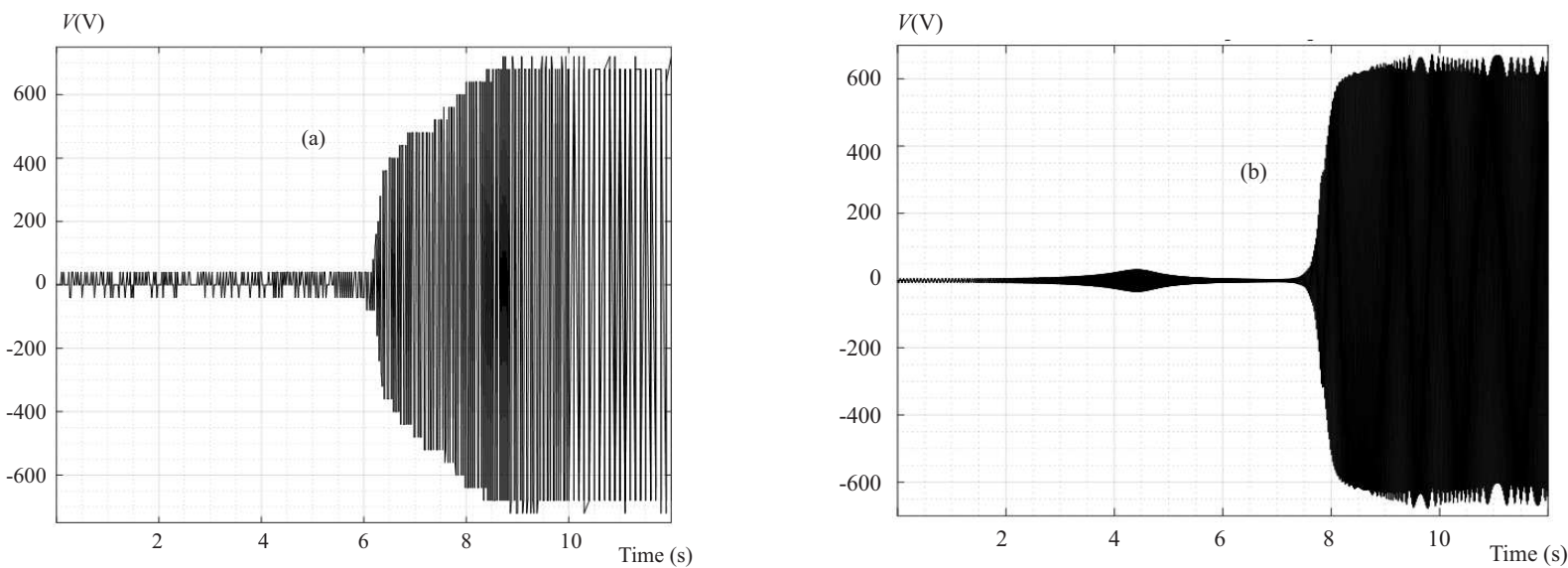

Fig. 8. Measured voltage build up on SEIG: (a) - measured, and (b) - simulated

Equivalent circuit parameters: $R_{F e}=22 \Omega, L_{m}=$ hence the magnetization curve (Fig. 6) was determined. $332 \mathrm{mH}, R_{1}=2.935 \Omega, R_{2}=0.145 \Omega, L_{1}=L_{2}=$ $45.39 \mathrm{mH}$.

A positive torque or speed was used to represent the "prime mover" (DC motor of the dynamometer). The initial value of stator terminal voltage was found, too. This voltage is related to the magnetic remanence in the core, Using 1:1 transformation ratio $\left(L_{1}=L_{2}\right)$ of machine windings, made the modelling and calculations somewhat simpler.

We use the forward Euler method for solving system of differential equations (2). The results of simulation
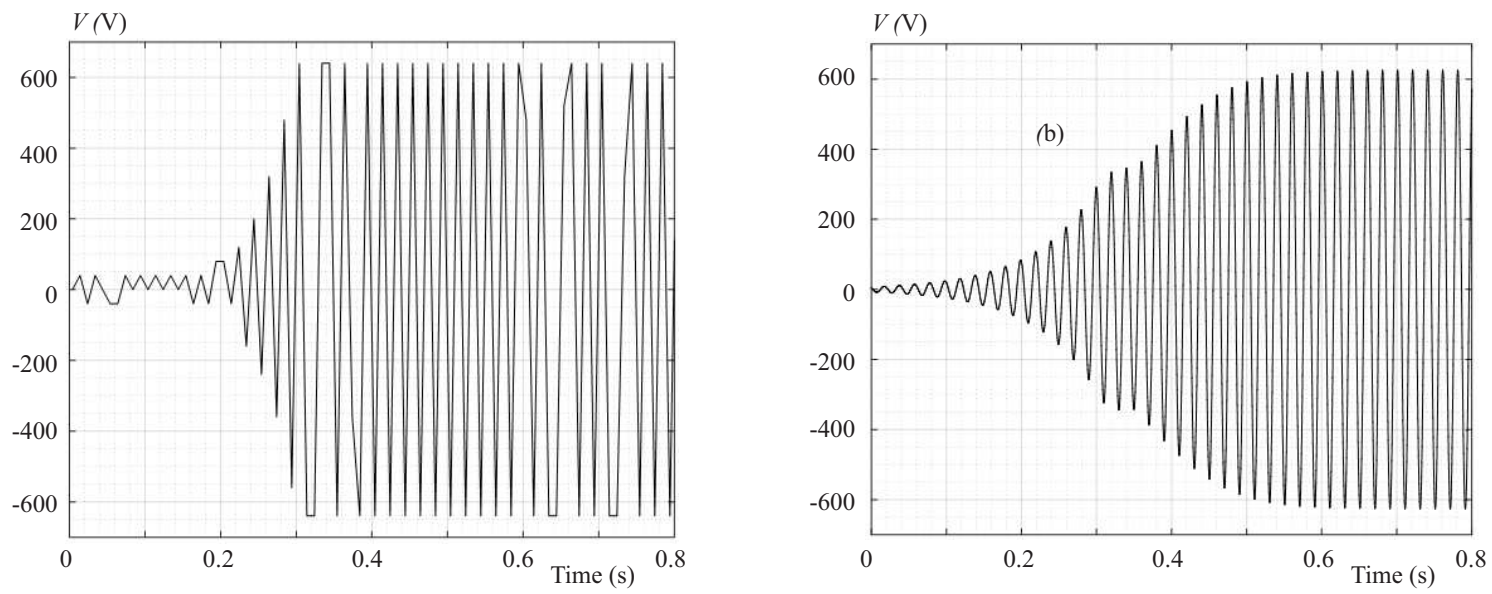

Fig. 9. No-load voltage of SEIG, after reaching the over synchronous speed: (a) - measured, and (b) - simulated
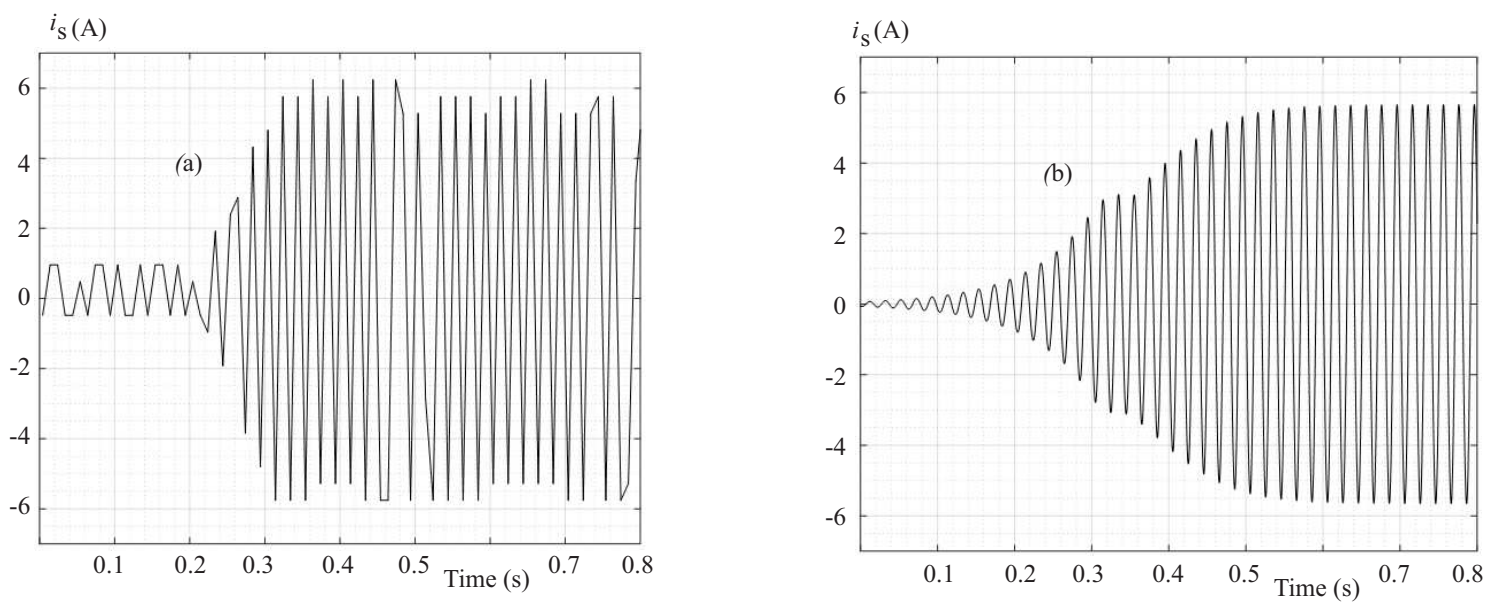

Fig. 10. No-load current of SEIG, after reaching the over synchronous speed: (a) - measured, and (b) - simulated 

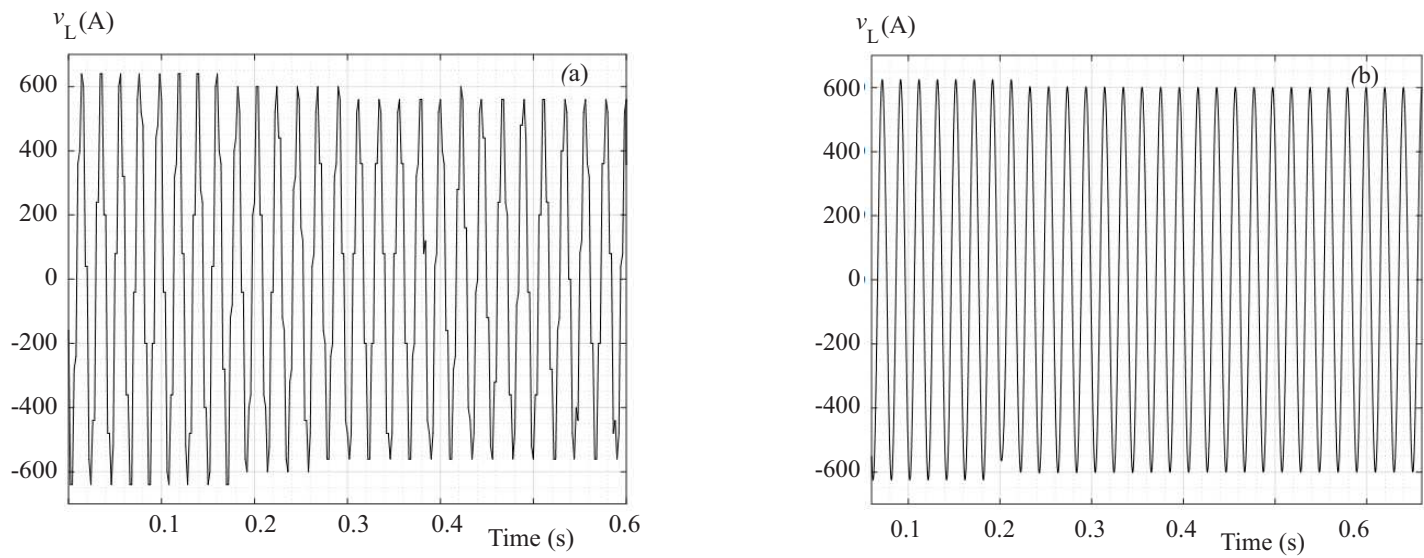

Fig. 11. Voltage on SEIG at a load of $250 \omega$ : (a) - measured, and (b) - simulated
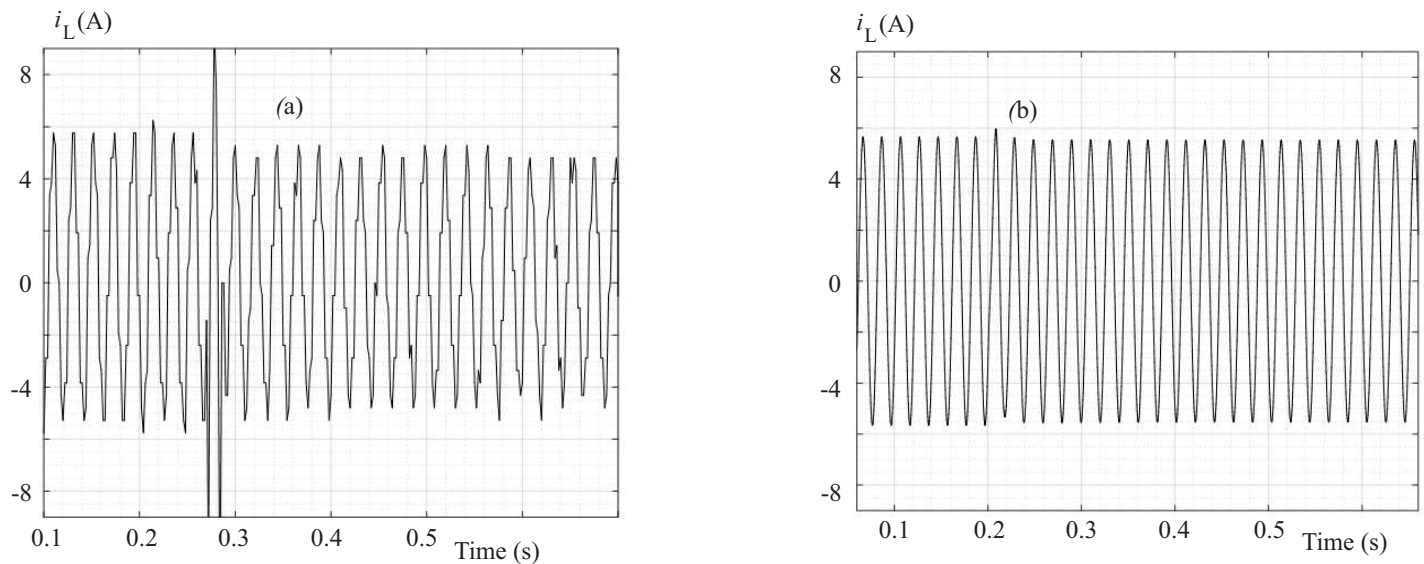

Fig. 12. Stator current at a load $250 \omega$ : (a) - measured, and (b) - simulated

at different conditions, namely with increasing load are compared below.

\subsection{Results of measurements and simulation on SEIG at no-load condition}

No-load self-excited induction generator tests were performed. The capacitor bank with three $50 \mu \mathrm{F}$ capacitors in wye connection was applied across the terminals of the investigated induction machine, Fig. 5. The self excitation process was achieved at a speed slightly above the synchronous speed.

At first we let the capacitor bank connected and the rotation speed was linearly increased until a full voltage was observed (Fig. 7). As shown in Fig. 8, the selfexcitation was achieved at $t=6.5 \mathrm{~s}$ and the full voltage was reached at $t=9 \mathrm{~s}$. This moment and the rotation speed when self-excitation begins depend on the remanent magnetism and capacitance of the connected capacitor bank. In Fig. 7(b) is the simulation result of interpolated speed and in Fig. 8(b) is the simulated voltage course.

In the subsequent experiment the machine was running at synchronous speed of $1500 \mathrm{rpm}$ with the capacitor bank connected but in no-load condition. The voltage build-up can be observed on the oscillogram, Fig. 9. The phaseto-phase voltage stabilized at a value according to the magnetization curve and applied reactive power from the capacitors. The value of the voltage reached slightly above $600 \mathrm{~V}$. In Fig. 10 one can see the peak value of the current reaching approximately $6 \mathrm{~A}$.

In Fig. 9 and Fig. 10 we can see the simulation results with the same initial parameters as in the experiment.

\subsection{Simulation and measurement with with resistive load}

In this series of measurements we have connected a resistive load on stator terminals, Fig. 11 and Fig. 12. A voltage drop and slip increase can be observed with an increasing load on the generator. This happens because the electromagnetic torque rises and decelerates the rotor shaft speed. We were able to change the load (wye connected rheostats) in range from $250 \Omega$ to $30 \Omega$ in each phase.

When the resistive load of $250 \Omega$ was connected to the stator terminals $(0.6 \mathrm{~s})$, switching transient phenomena causing spikes during 1 or 2 periods could be observed. After next few periods the operating point shifted (magnetization curve) and new values of the voltage (Fig. 11) and current (Fig. 12) appeared.

Resistive load of $50 \Omega$ applied on the stator terminals $(0.15 \mathrm{~s})$ caused the voltage, Fig. 13(A), and current, Fig. 14(a), to drop rapidly, although a new equilibrium 

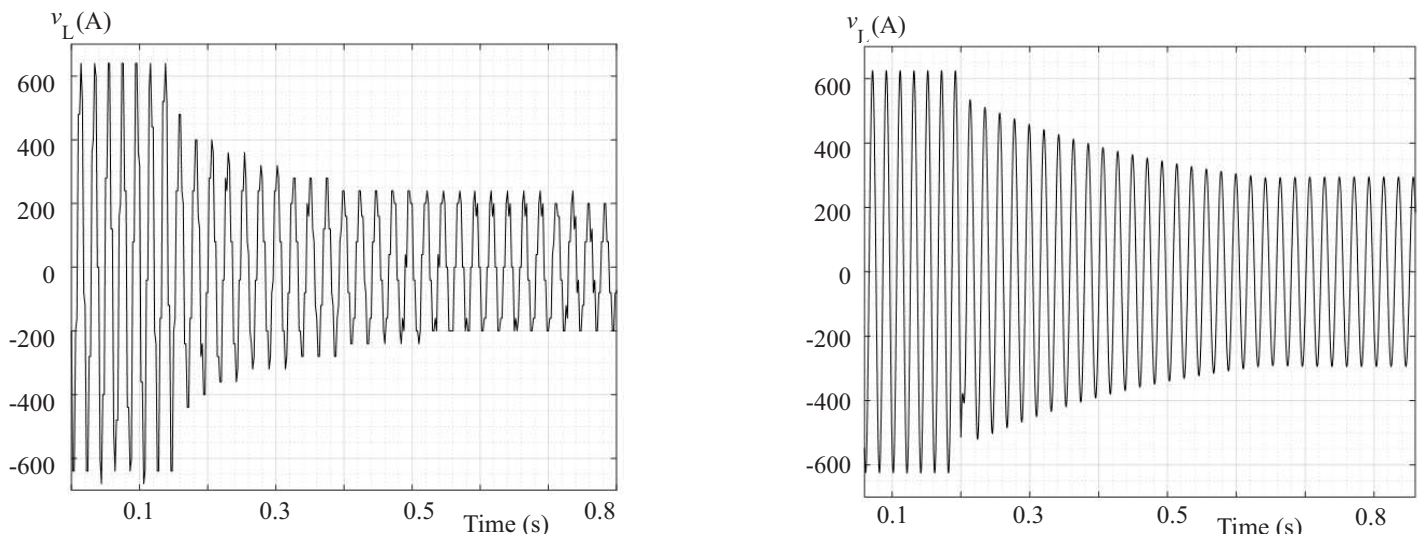

Fig. 13. Measured voltage build up on SEIG: (a) - measured, and (b) - simulated
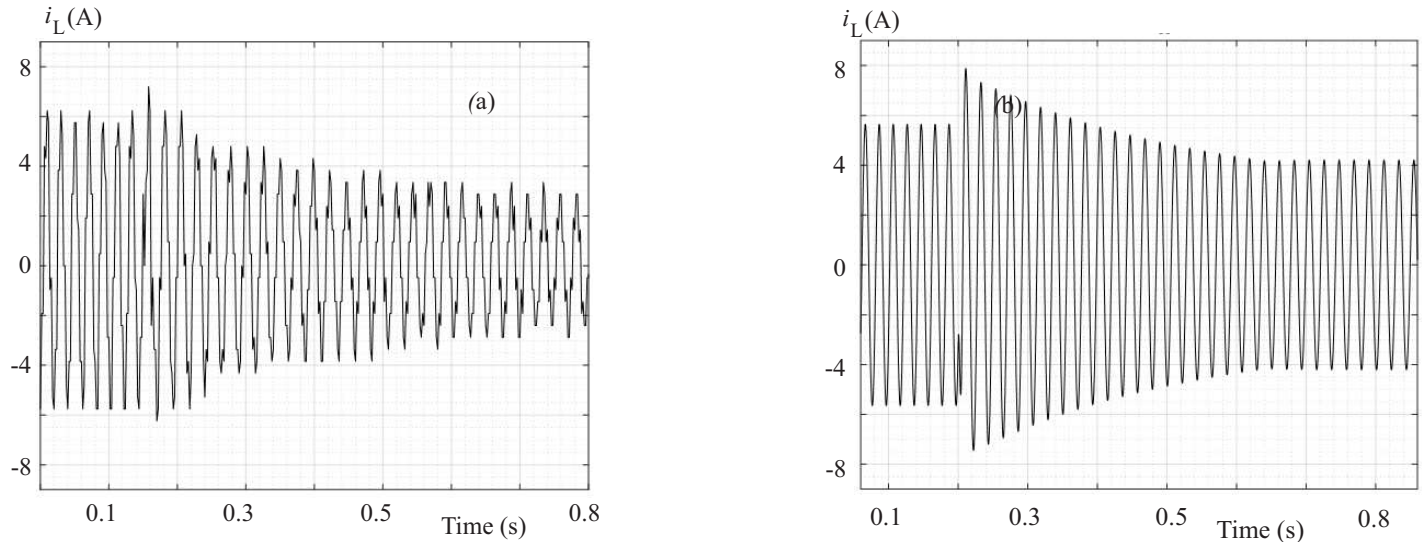

Fig. 14. Measured voltage build up on SEIG: (a) - measured, and (b) - simulated
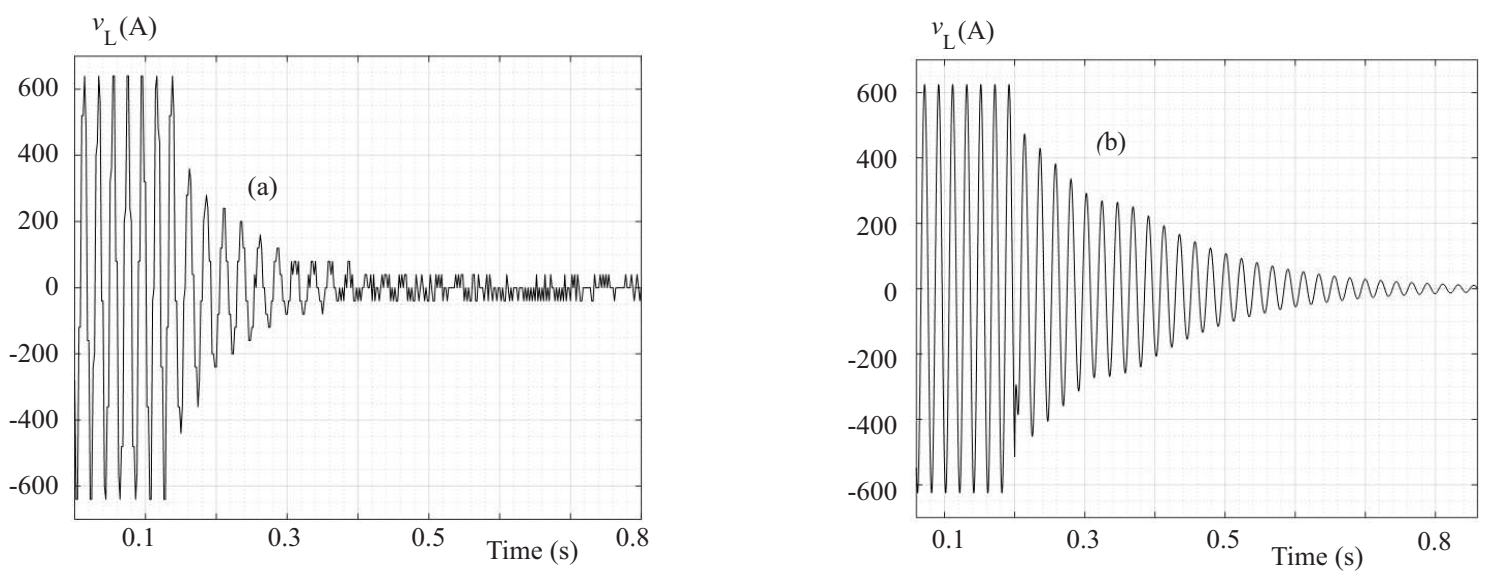

Fig. 15. Measured voltage build up on SEIG: (a) - measured, and (b) - simulated
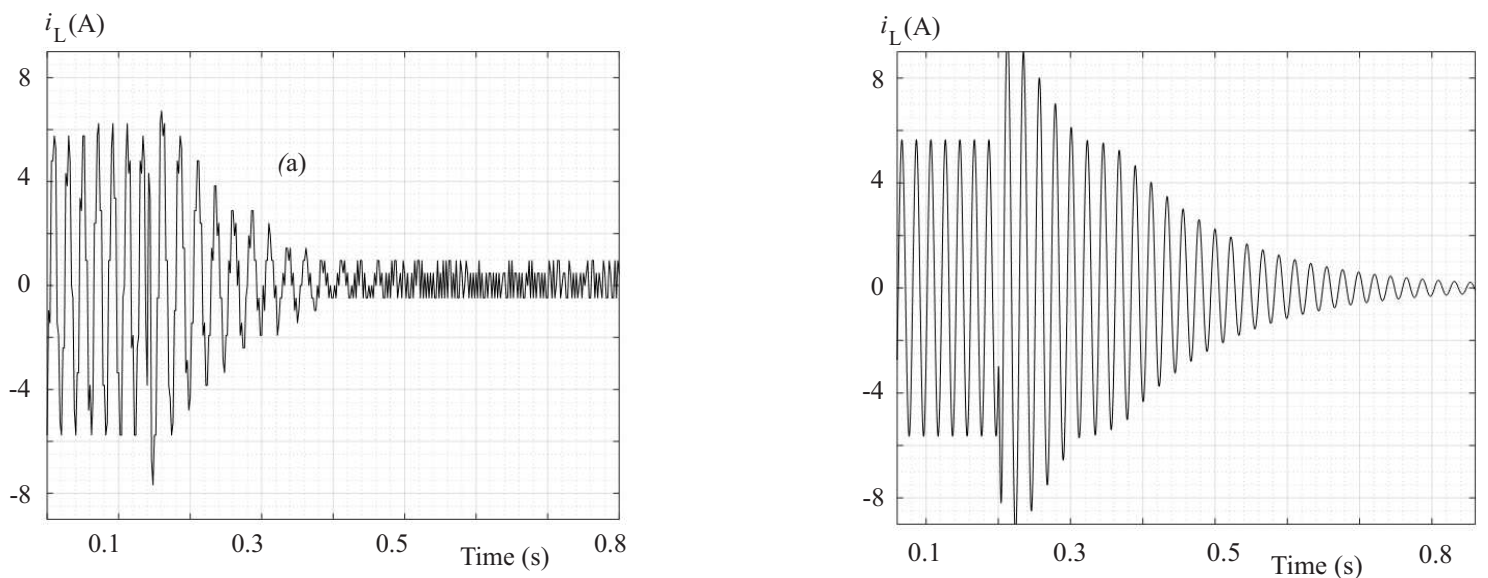

Fig. 16. Measured voltage build up on SEIG: (a) - measured, and (b) - simulated 
was reached. The peak value of the phase-to-phase voltage is about $250 \mathrm{~V}$ and the phase current decreased from approximately $6 \mathrm{~A}$ to $3 \mathrm{~A}$, which is well below the rated values.

Overloading of the machine with a load of $30 \Omega$ clearly resulted in an unstable state when the machine excitation was lost due to a lack of reactive power supplied from three $50 \mu \mathrm{F}$ capacitors.

\section{Conclusion}

Even if the induction machine itself is one of the oldest and most known machinery, its use in SEIG's role is of importance only in the recent years. This article presented partial results of a more complex study of the properties of SEIG in terms of its use in off-grid renewable power plants. We have investigated the self-excitation process using external capacitor banks and outlined the behaviours of the generator in variable (resistive) load conditions.

Experiments as well as simulations were proposed to compare and evaluate the measurement methods used and confirmed good correlation. However, further work is needed to be able to present more a comprehensive look on the research results such as regulation and control properties of SEIG.

\section{Acknowledgment}

This work was supported by the Slovak Research and Development Agency (APVV) under the Contract No. APVV-15-0326. This work is also the result of the project Competence center for new materials, advanced technologies and energy ITMS 26240220073, supported by the Research and Development Operational Program funded by the European Regional Development Fund.

\section{REFERENCES}

[1] M. G. Simoes and F. A. Farret, Renewable Energy Systems Design and Analysis with Induction Generator, CRC Press, 2004.

[2] C. F. Wagner, "Self-excitation of induction motors", AIEE Trans. Elect.

[3] Werner Leonhard, Control of Electrical Drives, Springer-Verlag, 2001, ISBN 978-3-540-41820-7.
[4] L. Wang, and J-Y Su, "Dynamic Performance of an Isolated Self-excited Induction Generator under Various Loading Conditions", IEEE Trans. Energy Convers., vol. 14, pp. 93-100, March 1999..

[5] J. Zuščák, F. Janíček, V. Kujan, M. Váry, "Dynamic behavior of self-excited induction generator in Off-grid operation under resistive load" Power engineering 2018, Control of Power Systems 2018, 13th International scientific conference. Tatranské Matliare, Slovakia. June 5-7, 2018. 1. ed. Bratislava, Slovak University of Technology, 2018, pp.89-94. ISBN 978-80-89983-00-1.

Received 11 September 2018

Jozef Zuščak was born in 1988. In 2014 he graduated (MSc) from the Institute of Power and Applied Electrical Engineering of the Faculty of Electrical Engineering and Information technology at the Slovak University of Technology in Bratislava. Since 2017 he has worked as a researcher at the Institute of Power and Applied Electrical Engineering. His scientific research is focused on off-grid energy systems, electric machines, substations and renewable energy sources.

Vladimír Kujan was born in 1980. In 2005 he graduated (MSc) from the Department of Electrical Machines and Instruments of the Faculty of Electrical Engineering and Information technology at the Slovak University of Technology in Bratislava. He works as a researcher at the Institute of Power and Applied Electrical Engineering. His scientific research is focused on electrical drives and power electronics.

František Janíček was born in 1954. He graduated from the Faculty of Electrical Engineering of the Slovak University of Technology in 1979. In 1984, he obtained the PhD degree in Power Engineering and in1999 he was appointed Professor. He has authored or co-authored 13 university textbooks and lecture books, 4 specialist monographs, more than 50 articles in journals and more than 100 presentations at international scientific conferences (of which 26 were guest lectures). He has put over 80 technical projects into practice. He is one of the co-founders of the internet-based information and education project INFELEN (information on power engineering). He is a member of the Slovak WEC SR committee, a statutory representative of the EE Association ( 8 organizations) and member of scientific boards of several universities in Slovakia. He reviewed several major projects in the field of liberalised power market and was a member of a team appointed to develop the Energy Policy of the Slovak Republic. Since 1 February 2006 he has been the Chairman of the Board for Technical Science with the Slovak Research and Development Agency. 